\title{
SOBRE EL “CUENTO” DE LA DUEÑA DOLORIDA
}

El hábil mayordomo del Duque, socarrón autor de la narración que nos interesa, urde una trama que tiene - con su juventud enamorada y su intervención dueñeril- algo de comedia de la época ${ }^{1}$; pero se aleja bastante de ese esquema literario, en primer lugar, por tener en cuenta a quien es el público principal de la misma, don Quijote. Ello justifica el fondo y algo de la forma caballeresca que conforman el relato: el rango de los protagonistas, que permite un contexto cortesano e imperial; la nominación de los personajes; la fabulosa intervención de Malambruno, gigantesco nigromante; y el encantamiento consiguiente, con su transformación simbólica de los protagonistas. Pero ni el eco de esquemas dramáticos ni las exigencias caballerescas de un narratario concreto explican del todo el conjunto cuentístico que resulta.

En el relato que llega hasta el público lector, ajeno a la escena de la narración, hay, tras el juego de exageraciones y fabulaciones necesarias y pertinentes a esa escena, una intención -y hasta una consecución- de "moralidad", una configuración narrativa que, a pesar de la capa de comicidad que todo lo tiñe, pretende una aleccionadora derivación ética de esa determinada serie de experiencias humanas. En este sentido, tanto la caracterización como la temática ofrecen ecos de una tradición celestinesca que uno de los principales ejes narrativos, la tercería, claramente promueve.

Los nombres de los protagonistas, que cumplen patentemente con las exigencias onomásticas de la re-creación cómico-caballeresca, contienen, además, un sentido bio-sexual, unlversalizante, que contribuye a esa sensación de "moralidad" que se desprende del relato. Antonomasia, pese a la procedencia retórico-gramatical y al exotismo altiso-

${ }^{1}$ De comedia de capa y espada, naturalmente, y siempre que la figura de la dueña refleje una caracterización más de criada-acompañante que de lujuria celestinesca, y que haya, desde luego, resolución feliz. Como se verá, ninguna de estas condiciones va a darse en el cuento cervantino. 
nante que satisfacen la norma cómico-caballeresca del Quijote ${ }^{2}$, no deja de proyectar su valor semántico sobre una trama que se organiza como una versión de ese "loco amor" que todos identificamos con La Celestina. Es la joven por "antonomasia", estopa que con consecuencias trágicas prende inevitablemente en contacto con el fuego que es el hombre, y su actuación será lección no menos explícita que la de Melibea.

Ese carácter de inevitable que el apelativo Antonomasia subraya de manera cómica y seria a la vez, tenía gran fuerza, recuérdese, en una sociedad que se estructuraba social, legal y hasta arquitectónicamente para evitar un contacto que hemos ofrecido, adrede, parafraseando el conocido refrán. El nombre del galán, don Clavijo, ofrece una conjunción parecida de efectos literarios. Es lo suficientemente exótico como para satisfacer, de inmediato, la necesidad cómico-caballeresca, función que refuerza semánticamente como masculinización que es de "clavija"; es decir, una cómica despersonalización cosificada de la aptitud guitarrera que caracteriza al personaje. Pero dentro del desarrollo temático del "loco amor" en que actúa el personaje no puede menos que pensarse en la otra acepción del término, también masculinizado para el caso: "taruguillo [...] que se usa [...] para tapar un agujero". Es decir, que otra cosificación paralela universaliza en el onomástico de don Clavijo el impulso bio-sexual de su sexo.

Esta fijación sexual universalizante de los protagonistas apoya el esquema de "moralidad" celestinesca que presenta el corto argumento que idea el mayordomo socarrón: la intervención de la tercera, que permite el contacto - con las consecuencias previsibles, de inevitable prendimiento - entre la que es joven por antonomasia y el que viene a representar, no menos cómico-simbólicamente que ella, la impulsiva sexualidad del joven, y que no deja de contaminar a esos amores "locos" por incontrolados de resabios trágicamente celestinescos; y la imposición de impedimentos (de tipo social y político, en este caso) que dificultan la acostumbrada resolución meramente matrimonial del problema amoroso y conducen, efectivamente, a la trágica muerte de la reina-madre. Todo ello produce un conjunto narrativo que ha de desembocar, si no en la muerte, en la manera propiamente celestinesca, sí en la aparición justiciera, castigadora, de Malambruno y en el consiguiente encantamiento de la pareja "desquiciada".

Esta aproximación de la caracterización y de la trama del "cuento de la Dueña Dolorida" al esquema de una obra celestinesca — de "loco amor" con tercería como elemento catalítico, con consecuencias lamentables y hasta trágicas - ha de tomarse, desde luego, con esos granitos de sal paródicos que informan a todo el Quijote. No se escapa, en éste, esquema literario alguno (esquemas de fijación renacentista, percibidos con ojos peculiarmente barrocos ${ }^{3}$ ) de la parodia del gran novelista, y

2 Véase H. Mancing, "The Comic Function of Chivalric Names in Don Quijote", Names, 21 (1973), 220-235

${ }^{3}$ Como se sabe, no sólo la literatura caballeresca, sino la pastoril y hasta la pica- 
no habría de ser excepción el esquema de "moralidad celestinesca" con el que vemos parentesco claro en lo urdido por el malicioso mayordomo. El mero esfuerzo por adecuar semejante esquema a su blanco principal, don Quijote, exige un proceder paródico, de alteraciones y adiciones cómico-caballerescas: en los nombres mismos (aunque destaquen simultáneamente acepciones que refuerzan el esquema básico), en las inserciones fabulosas (el inevitable gigante, aunque su justiciera actitud sea instrumento del necesario castigo de los amantes "locos") y en el castigo mismo, de encantamiento que, como todos los del Quijote, posee patentes visos cómicos.

Mas el encantamiento, la transformación zoomórfica de los protagonistas, da también que pensar, procediendo como procede de nuestro parodista por excelencia. Sin pensar en disminuir ni desdibujar la comicidad "caballeresca" que posiblemente proceda de su anomalía (insertando en el cuadro caballeresco una manera de transformación del tipo que abunda en la literatura folklórico-popular), la manera concreta del encantamiento y de su presentación literaria sugiere alguna otra y añadida intención paródica:

...el cual (Malambruno) con sus artes, en venganza de la muerte de su cormana, y por castigo del atrevimiento de don Clavijo, y por despecho de la demasía de Antonomasia, los dejó encantados sobre la mesma sepultura, a ella, convertida en una jimia de bronce, y a él, en un espantoso cocodrilo de un metal no conocido, y entre los dos está un padrón, asimismo de metal, y en él escritas en lengua siriaca unas letras... (II, 39)

Despierta nuestra curiosidad, en primer lugar, el simbolismo animal que pretende el novelista ${ }^{4}$, ya que resulta impensable que fuese arbitraria la selección de la jimia para el encantamiento de Antonomasia y del cocodrilo para el de don Clavijo. Por tratarse de animales, y de dos que en su vida humana hubieron de relacionarse entre sí, lo primero que se nos ocurrió es que ello recogiera el contenido didáctico-simbólico de alguna fábula. Mas nuestra búsqueda en esa dirección resultó infructuosa, y no porque faltaran fábulas cuyos protagonistas fuesen el mono y el cocodrilo, sino porque no parecen haber llegado las tales - lógicamente procedentes de la India o Egipto ${ }^{5}$ a las colecciones de

resca tienen su representación paródica en el Quijote. Todas estas formas, así como las que sacaremos a relucir en estas páginas, cristalizan en el Renacimiento.

4 "Sirven [los animales que dice abundan en la Segunda Parte] para introducirnos en la sociedad y en el mundo turbio de las pasiones, llegando a cristalizar en la jimia de bronce y el cocodrilo de un metal desconocido, grupo simbólico que adorna la sepultura de la Humanidad". Este juicio del profesor Casalduero, Sentido y forma del Quijote, Ínsula, Madrid, 1949, p. 212, no precisa, como se ve, acerca de las concreciones animales que aparecen en el texto cervantino. La crítica cervantina, por lo general, se ha contentado con esa identificación imprecisa.

${ }^{5}$ Para la colección de los Jataka, procedentes de la India, véase, por ejemplo, Buddist Birth-Stories (Jataka Tales), traducidos de la edición del texto pali de V. Faustböll por 'T. W. Rhys Davids, G. Routledge \& Sons, London, s.a. 
ejemplos ibéricos sin alterar sus elementos animales ${ }^{6}$. Bastante más éxito tuvimos en nuestra búsqueda de valores simbólicos para el mono y el cocodrilo - aunque ya por separado- al consultar los "fisiólogos", o bestiarios medievales, pensando que sus descripciones simbolizadoras hubieran podido retener vigencia de tradición hasta la época de Cervantes $^{7}$. En este sentido, los valores simbólicos tradicionalmente adscritos a esos dos animales refuerzan el desarrollo temático del "Cuento de la Dueña Dolorida" y explican lo concreto de la transformación malambrunesca: lujuria en la jimia ${ }^{8}$, y lujuria e hipocresía en el cocodrilo ${ }^{9}$.

El encantamiento-castigo cuadra emblemáticamente, pues, con la conducta humana que tal castigo exigía; pero resta por explicar, o intentarlo, el carácter del emblema que acabamos de comentar en su sentido simbólico:

...sobre la mesma sepultura, a ella, convertida en una jimia de bronce, y a él, en un espantoso cocodrilo de un metal no conocido, y entre los dos está un padrón, asimismo de metal, y en él escritas en lengua siriaca unas letras, que habiéndose declarado en la candayesca, y ahora en la castellana, encierran esta sentencia...

Su descripción iconográfica no puede menos que recordar otra probable fuente de la imaginística animal que utiliza Cervantes: la emblemática ${ }^{10}$. La fijación iconográfico-simbólica no ocurre otras veces en el Quijote ${ }^{11}$, y por ello mismo adquiere interés especial el caso que

${ }^{6}$ Un buen ejemplo, por lo preciso del paralelo, es "Del galápago y del ximio" de Calila y Dymna, que en la colección Jataka lleva cocodrilo en vez de galápago. No hemos hallado al cocodrilo en ninguno de los fabularios consultados.

${ }^{7}$ Como ejemplo, tratándose del cocodrilo, The Bestiary, ed. y tr. T. H. White, G. P. Putnam \& Sons, New York, s.a., p. 50: "Hypocritical, dissolute and avaricious people have the same nature as this brute...' Para un resumen moderno de esta literatura, con útil bibliografía, véase Anne Clark, Beasts and Bawdy, J. M. Dent \& Sons, London, 1975.

${ }^{8}$ Véase, en particular, H. W. JAnson, Apes and Ape Lore in the Middle Ages and Renaissance, University of London Press, London, 1952, pp. 109, 115, 261-262. Curiosamente, y aunque sería demasiado arriesgado afirmarlo - aunque pertinente al cuento cervantino- la jimia se identificaba, asimismo, con el parricidio (p. 182).

${ }^{9}$ Véase, en particular, G. C. Druce, "The Symbolism of the Crocodile in the Middle Ages"', The Archeological Journal, 66 (1910), núm. 264, pp. 315, 318. El carácter metálico de las figuras de animales, en particular el bronce de la jimia, también se presta, aunque más arriesgadamente, a la interpretación lujuriosa: en el sueño de Nabucodonosor la figura tiene de bronce, precisamente, el vientre y los lomos. También es de interés - aunque sólo porque su fijación de lo exótico podría ser pertinente en el cuento cervantino- que dos de los tres animales identificados con el Nuevo Mundo en la época de Cervantes (caimán, mono y papagayo) figuren en él; véase, por ejemplo, Alejo Carpentier, El camino de Santiago.

${ }^{10} \mathrm{El}$ mono abunda en semejante literatura; el cocodrilo menos, pero también aparece: véase, por ejemplo, Paolo Giovio, Dialogo dell'Imprese Militari et Amorose, Scholar's Facsimiles \& Reprints, New York, 1976, p. 118

11 Para el uso de fuentes emblemáticas en el Quijote, aunque no se refiera a repro- 
comentamos, pues parece ofrecer dejos paródicos de esa modalidad literaria que tanto auge tuvo hasta la época de Cervantes ${ }^{12}$.

Varios aspectos de esa representación emblemático-jeroglífica (sin tomar en cuenta, que bien se pudiera, el contexto de exageración cómicocaballeresca en que queda incorporada) sugieren una intención paródica que nada extrañaría, por otra parte, en Cervantes ${ }^{13}$. La ausencia de poema explicativo, por ejemplo ${ }^{14}$, pudiera muy bien resaltar críticamente la redundancia fundamental de esa modalidad literaria, en la que huelga lo literario o lo iconográfico. Y la exageración detallista ("jimia de bronce"'), que consigue incorporar, con todo, una indefinición conscientemente confusa ("espantoso cocodrilo de metal desconocido") ${ }^{15}$, es también un consagrado proceder caricaturizante y paródico.

En conclusión, el análisis del "Cuento de la Dueña Dolorida" ha resaltado el carácter paródico de su conjunto. Por una parte, Gervantes utiliza elementos de tradición caballeresca - elementos perfectamente adecuados al contexto en que se narra todo- para contaminar, con el consiguiente humor paródico, un esquema que es fundamentalmente de índole celestinesca, esquema éste no menos apropiado dado el supuesto carácter de la "narradora". Por otra parte, pensamos que es muy posible que Cervantes se valiera de uno de los deformantes elementos "caballerescos", el encantamiento, para ofrecer una presentación paródica, cómica, de la literatura emblemático-jeroglífica.

\section{Rosa Fernández y Alfred Rodríguez}

The University of New Mexico

ducciones emblemáticas en éste, véase P. L. ULIman, "An Emblematic Interpretation of Sansón Carrasco's Disguises', $H H H$, pp. 223-238.

12 El profesor Ullman se refiere expresamente a la posible influencia del libro de Sebastián de Covarrubias, Emblemas morales, publicado en 1610. La emblemática no era ajena, tampoco, al género novelístico que Cervantes parodia en el Quijote; véase Mario Praz, Studies in Seventeenth-Century Imagery, The Warburg Institute, London, 1947, t. 2, 55.

13 Cervantes se burla del uso de emblemas y jeroglíficos en el primer poemaelogio del Quijote (Urganda la desconocida), y también al referirse a LÓPEz DE Ú BEDA, autor de La picara Justina, en su Viaje del Parnaso.

14 Podía darse, como en el citado libro de Covarrubias, la imagen simbólica, un poema explicativo (parte indispensable de la modalidad literaria) y una interpretación en prosa moralizante.

${ }^{15}$ Aunque pudiera arrastrar intención simbólica en sí (véase n. 9), lo más factible es que el detalle metálico, especialmente lo de "desconocido", no tuviera más finalidad que un cómico y confuso seudo-simbolismo. 